\title{
FEMINISMO Y LITERATURA. ACERCA DEL CANON Y OTRAS REFLEXIONES
}

\author{
MARÍA JESÚS FARIÑA BUSTO
}

Universidad de Vigo mbusto@uvigo.es

RESUMEN: En gran medida, continúan vigentes muchas de las cuestiones que el pensamiento feminista sobre la literatura ha planteado de forma reiterada desde sus inicios: por qué las escritoras no aparecen en las historias literarias ni en los programas académicos, por qué la crítica literaria continúa ignorándolas o devaluando sus textos, por qué definirse como feminista produce todavía malestar a las propias escritoras. A estos y otros aspectos se refiere este artículo en proyección histórica y reflexiva.

PALABRAS CLAVE: Canon, Literatura, Feminismo, Representación, Historia literaria, Escritoras Ibéricas. 


\section{FEMINISM AND LITERATURE. On the canon and other reflections}

ABSTRACT: To a large extent, many of the issues that feminist thinking on literature has repeatedly raised since its inception are still valid: why female writers do not appear in literary histories and in academic curricula, why literary criticism continues to ignore or devalue their texts, and why defining oneself as a feminist still discomforts female writers themselves. These and other aspects are referred to in this article, taking into account their historical and reflective projection.

KEY WORDS: Canon, Literature, Feminism, Representation, Literary history, Iberian Women Writers.

Si la escritura de la Historia progresa [...] lo hace no sólo a través del descubrimiento de nuevos materiales sino también a través de una nueva lectura de esos materiales.

Lola Luna

$\mathrm{D}$ esde muy distintos ángulos puede ser abordada la conjunción Literatura y Feminismo. De entre ellos, al menos tres serían relevantes: atendiendo a su relación con las diversas instituciones literarias (entiéndase, al respecto, el ámbito académico, editorial y de premios), atendiendo a los modos críticos sobre los textos (es decir, desde la interpretación) y atendiendo a los propios textos y a sus artífices (es decir, desde la escritura).

Los dos primeros se vinculan estrechamente con la cuestión del canon, su formación y sus funciones; el tercero remite a los tex- tos, a sus objetivos y sus estrategias, a los valores que rebaten o a las representaciones que construyen. Existe ya una bibliografía relevante al respecto; trazaré aquí, únicamente, un breve estado de la cuestión inscribiéndolo en su perspectiva histórica.

\section{El canon en disputa}

Que haya mencionado en primer lugar las instituciones literarias se debe al hecho importantísimo de tratarse de formadores del canon, es decir, de instituciones determinantes a la hora de establecer qué textos y qué autores deben ser incluidos dentro de esa selecta lista de obras maestras que lo constituyen. Como escribe Iris M. Zavala:

El canon implica un proceso de selección y de exclusión, y supone a su vez una serie de instituciones que forman el canon, entre otras, naturalmente, la escuela y la Universidad. Los críticos literarios somos agentes que ayudan a formular el canon y sus exclusiones o reducciones. Otras formas institucionalizadas son las historias literarias, las ediciones de los textos, los estudios literarios o culturales, los diccionarios, las enciclopedias, las reseñas, las academias, los premios. [Énfasis en el original] (1993: 65-66)

Son muchas, pues, las instituciones y los agentes que colaboran a la construcción y formulación del canon y, parece notorio, lo hacen respondiendo a intereses de muy distinto signo, aunque posiblemente todos coinciden en la defensa de un conjunto de valores que la tradición y la ideología patriarcal, al menos en esto que llamamos Occidente, han instituido en norma, en principio, en centro.

Entre los agentes, sin duda la crítica constituye uno de los más activos, y no sólo la crítica académica sino también aquella destinada a la divulgación. En general, la crítica estima o desestima una obra según criterios que hace pasar por objetivos e imparciales, pero no podemos olvidar que, al igual que la historia literaria y que la propia cultura, la crítica ha tenido una clara sustentación androcéntrica y misógina. La teoría feminista nos ha enseñado que una posición

UNED. REI, 4 (2016), pp. 9-41

ISSN 2340-9029 
interpretativa nunca es neutral, que siempre se ejerce desde un lugar y que ese lugar, consciente o inconscientemente, es un nudo de creencias, de valores y de supuestos. La neutralidad es, como poco, un desiderátum difícil de alcanzar, por eso resulta fundamental definir el lugar desde el que hablamos.

En ocasiones, y con frecuencia referidos a las obras de escritoras, los comentarios valorativos han ocupado la superficie del discurso crítico casi podría decirse que obscenamente y resulta muy revelador comprobar cómo la ideología de quien los emite se sobrepone a los textos desplazando el foco de atención desde ellos hacia un territorio no pertinente para el análisis ${ }^{1}$. Tales comentarios no pasan desapercibidos a una lectora actual, obviamente no a una lectora feminista $^{2}$, atenta a los múltiples hilos del código patriarcal, uno de los cuales ha consistido, precisamente, en desviar la atención desde la obra hacia la vida de las escritoras. Es bien patente en el comentario de González de Amezúa transcrito en la nota, en su caso, además, sin ofrecer datos, solo recurriendo a consideraciones totalmente impresionistas; y no pretendo insinuar, al hacer esta observación, que haya que ocultar hechos de la vida de un/a autor/a, pues sabemos que a veces un dato biográfico puede instituirse en clave de escritura y de lectura, pero una cosa muy distinta es la valoración que se hace de esos datos o la perspectiva adoptada frente los mismos.

${ }^{1}$ Un ejemplo muy expresivo es el de uno de los editores de los Desengaños amorosos de María de Zayas, Agustín González de Amezúa, quien, entre otras cosas, dice "Pocos autores de aquel tiempo poseen en tanto grado su poder descriptivo [...] Doña María, como mujer, ama el detalle, el orden casero, la organización del hogar [...] Tengo para mí que, además de escritora y poetisa, fue doña María excelente ama de casa, coincidencia y circunstancia que se ha dado también en algunas otras escritoras modernas que siguieron sus pasos en la senda de la novela" (1950: xiv).

2 En palabras de Lola Luna (1996: 24), "leer como una mujer significa revisar axiológicamente, desde una perspectiva feminista, las lecturas y modos de lectura que nos han configurado como lectores, y que nos han transmitido simultáneamente modelos de identidad sexual mediante roles o estereotipos sociales, arquetipos $y$ mitos".

UNED. REI, 4 (2016), pp. 9-41
Anotaciones similares, y tan prescindibles, se repiten en manuales mucho más próximos en el tiempo, al igual que se repite otro tipo de afirmaciones, concordantes con el mismo imaginario, en textos académicos ya publicados en la frontera del siglo veintiuno ${ }^{3}$ o ya entrado este siglo ${ }^{4}$. Pero no sólo críticos e historiadores de la literatura, muchos intelectuales y escritores juzgaron el trabajo de sus contemporáneas ajustándose totalmente a los presupuestos canónicos, sin ningún cuestionamiento al respecto. Lo significativo es que, a través de sus palabras, al mismo tiempo que la jactancia y el agravio, podemos leer también otra cosa: que las escritoras seguían desarrollando su actividad y defendiendo, contra viento y marea, un territorio del que se consideraban dueñas tan naturales como sus compañeros. Así se deduce de la siguiente declaración de Rubén Darío en una de sus crónicas:

En este siglo las literatas y poetisas han sido un ejército, a punto de que cierto autor ha publicado un tomo con el catálogo de ellas - y no las nombra a todas-. [...] En cuanto a la mayoría innumerable de Corinas cursis y Safos de hojaldre, entran a formar parte de la abominable sisterhood internacional a que tanto ha contribuido la Gran Bretaña con sus miles de authoresse [sic]. ${ }^{5}$ (1901: 381-382)

${ }^{3}$ En la introducción al volumen de Actas de un Congreso celebrado en 1999, no deja de sorprender el siguiente comentario: "Ahora vamos a analizar algo mucho más etéreo y difícil de definir, pues partiendo de una materia muy sugestiva - la mujermeditaremos sobre las repercusiones que lo femenino, en su sentido más amplio, ha podido tener en la obra narrativa española contemporánea" [Énfasis mío] (Cuevas, 1999: 7).

${ }^{4}$ Cabría recordar, al respecto, el debate surgido hace unos meses a propósito de unas afirmaciones del editor Chus Visor en una entrevista en El Cultural (26/06/2015): "Lo siento, pero creo que la poesía femenina en España no está a la altura de la masculina, digamos, aunque tampoco es cosa de diferenciar" (http://www.elcultural. $\mathrm{com} /$ revista/letras/Chus-Visor-Dicen-que-los-novelistas-son-vanidosos-perohay-cada-poeta/36667

${ }^{5}$ Rubén Darío se refiere a las poetas de su siglo. Aunque salva a algunos "grandes árboles" (Carolina Coronado, Emilia Pardo Bazán, Concepción Arenal), denigra con sarcasmo a la mayoría; nada similar, en cambio, con respecto a muchos poetas a los que, sin duda, podría dedicar términos equivalentes.

UNED. REI, 4 (2016), pp. 9-41

ISSN 2340-9029 
Para el autor nicaragüense, el destino de las mujeres era otro, como pone de manifiesto a lo largo de “¡Estas mujeres!”, donde se posiciona en contra del voto de las mujeres en principio despreciando a las sufragistas y finalmente expresando el pensamiento al que en realidad quiere llegar:

las propagandistas son solamente unas cuantas, viejas y feas. Las pocas jóvenes y algunas guapas, si lo hacen, lo hacen por divertirse. Las demás mujeres, de belleza o de gracia, seguirán ejerciendo el único ministerio que la ley de la vida ha señalado para ellas: el amor en el hogar, o el amor en libertad. (1912: 36)

Crónicas y artículos periodísticos desempeñaron un papel nada desdeñable como medios de divulgación de opinión al llegar a un público más amplio y contribuyeron, de ese modo, a la difusión y asentamiento de prejuicios y de creencias injustificadas, aunque asentadas en tradiciones predeterminadas como naturales ${ }^{7}$, que eran expresadas, no lo olvidemos, por figuras de autoridad en su ámbito, como es el caso de Rubén Darío. Funciones equivalentes juegan hoy los suplementos literarios y no importa, en este sentido, el signo más o menos conservador de los mismos: favorecen a ciertas editoriales, difunden a ciertos autores (muy pocas autoras) y perpetúan ciertos

${ }^{6}$ Escribe: "Siguiendo a las alborotadoras inglesas he aquí que también en esta Francia del encanto femenino las mujeres quieren votar, y quieren ir al Congreso. Tengo a la vista unas cuantas fotografías de esas políticas. Como lo podréis adivinar todas son feas; y la mayor parte más que jamonas [...] Que las mujeres persisten en querer hacer muchas cosas que hacen los hombres y que hay algunas que superan la competencia masculina: perfectamente. Pero estas marivarones - suavicemos la palabra- que se hallan propias para las farsas públicas en que los hombres se distinguen... merecen el escarmiento” (1912: 34-35). “Estas mujeres!” forma parte de la sección "Films de Paris" de Todo al vuelo (1912)

${ }^{7}$ En un artículo de 1892 Pardo Bazán se refería a estos prejuicios con su siempre bien alentado discurso: "la llamada cuestión de la mujer [...] vendrá por la suave fuerza de la razón a imponerse a los legisladores y estadistas de mañana, y parecerá tan clara y sencilla (no obstante sus trascendentales consecuencias) como ahora se les figura de intrincada y pavorosa a los cerebros débiles y a las inteligencias petrificadas por la tradición del absurdo" (1999: 193).

UNED. REI, 4 (2016), pp. 9-41 parámetros críticos ${ }^{8}$. Todo ello como consecuencia de un entramado simbólico devaluador de lo femenino que quienes reseñan o catalogan se limitan a reproducir sin rebatir y, aunque a veces cuesta aceptar que personalidades brillantes en la literatura o en cualquier otra disciplina sean incapaces de reconocer las iguales competencias intelectuales y creativas de todos los sujetos, independientemente de su sexo o de otra variable, la realidad es que sus testimonios han quedado ahí, fijados por la escritura.

En todo caso, y a pesar de esta larga e ininterrumpida historia de misoginia, y a pesar de que algunas (o tal vez bastantes) de estas actitudes aún permanezcan, la práctica y la crítica feminista han producido movimientos de calado tanto en la historia literaria como en el modo de situarse ante los textos. Según lo expresan Saba Bahar y Valerie Cossy: "la prise de consciente féministe a conduit á repenser l'objet littéraire et à reformuler son histoire" (2003: 4), dos extremos fundamentales de refutación del canon. Porque repensar el objeto literario supone tanto repensar los sistemas axiológicos que sustentan las categorías legitimadas sobre lo literario (lo que conlleva, a su vez, e inevitablemente, desplazamientos que repercuten, por ejemplo, en la manera de entender los centros y los márgenes de esa historia), cuanto repensar los propios procedimientos empleados para configurar tal historia, lo que concierne a las instancias emisora y receptora así como a los criterios de agrupamiento - cronológicos, estéticos, sociológicos - de los textos. Esto quiere decir, como señala Lola Luna, que una "historia literaria de corte tradicional que tenga en cuenta el género sexual debería revisar los cuatro conceptos básicos que la sustentan: la periodización histórica, el concepto de género y estilos literario, el concepto de 'autoría' y la función del lector en la transmisión y recepción de textos” (1996: 105) ${ }^{9}$. E Iris M. Zavala en-

${ }^{8}$ Sobre la escasez de escritoras premiadas y reseñadas críticamente, remito a los artículos de Laura Freixas (2005, 2007, 2008 y 2013) y a su libro La novela femenil y sus lectrices (2009).

9 El ensayo al que pertenece la cita, "Las lectoras y la Historia literaria", tiene como objetivo determinar "cuál ha sido la participación de las lectoras en la constitución del canon literario y [...] cuál ha sido el modelo interpretativo de lectora que los 
fatiza: "Parece evidente que ninguna historia literaria moderna puede silenciar la deuda con las grandes pioneras del análisis feminista actual [...] ni la crítica de una crítica que quiere pasar por verdades mentiras sostenidas por tropos retóricos" (1993: 31). Ya no es fácil, en consecuencia, sostener una idea de naturalidad ${ }^{10}$, de inmovilidad o de imparcialidad del canon, como tampoco eludir el estudio de la obra de las escritoras (sean obedientes o rebeldes) o no afrontar los textos, sea cual sea su autoría, o la propia historia literaria con una perspectiva de género o feminista ${ }^{11}$.

Si el canon ha sido constituido desde una mirada androcéntrica (que expulsa a las mujeres a los márgenes - y a las escritoras a la mudez, al menos pública- y legitima ciertos valores y temas), el debate sobre el canon exige evaluar los procedimientos que lo perpetúan, quizás no reconstruyéndolo o creando cánones alternativos

textos culturales han creado y transmitido" (Luna, 1996: 102). La lectura, por lo tanto, entendida como otro importante agente del canon, lo que nos obliga a preguntarnos cómo leemos, a quién/es, desde dónde.

${ }^{10} \mathrm{Nada}$ de natural tiene el canon: "A pesar de que tradicionalmente se ha sostenido que la selección del canon es un proceso 'natural' que criba las obras por su calidad - estética o de otro tipo-, la realidad es que en su conformación operan muchos factores y que los juicios estéticos nunca tendrán valor si no se realizan en ciertos contextos institucionales y se reiteran en el tiempo para sucesivas generaciones de lectores. Porque el canon [...] es una cuestión de poder, del poder que impone en cada generación a unos autores sobre otros y que deja a las mujeres en los márgenes" (Baranda, 2007: 1).

${ }^{11}$ Quiero señalar los matices entre los estudios de género y los estudios feministas. Por una parte, como escribe Lourdes Méndez (2005: n.p.), "los estudios de 'género' pueden partir de perspectivas de investigación feminista, pero también pueden no hacerlo". Por otra parte, y en términos de Teresa Joaquim (2004: 89), que lo reflexiona desde el ámbito portugués: "A categoria analítica de género tornou-se mais presente [...] nos anos 90, tendo como nó fulcral os aspectos relacionais da construção social do feminino (e do masculino). Tornou-se numa palavra passe-partout, nomeadamente na sua emigração e tradução em contextos institucionais cuja utilização - nessa tradução institucionalizada - é muitas vezes indevida, por escamotear a crítica que essa categoria analítica implica, podendo-se fazê-la 'despolitizar' a luta das mulheres. Categoria analítica que se tornou um contributo teórico importante, mas que não é reconhecido na sua fonte, que é 'cortada' da área dos estudos sobre as mulheres, das teorias feministas, havendo neste caso a despolitização também do conceito". (o quizás también) sino desentrañando sus mecanismos de funcionamiento e interrogándonos sobre su sentido y necesidad, buscando enfocar el problema desde múltiples ángulos. Desde luego, es fundamental incorporar a las escritoras en la serie histórica, en los programas académicos, en la investigación y en la recepción literaria; a través de sus textos hablaron del mundo - de un mundo del que ellas formaban una parte reprimida y desautorizada - y de sus formas de resistencia frente a él. Pero la cuestión va más allá, como también afirman Bahar y Cossy:

La critique féministe du canon et de l'historie littéraire ne se contente ni de assurer une meilleure représentation des femmes dans le canon, ni de montrer que les oeuvres sont conformes aux critères esthétiques requis; elle invite à de nouvelles façons de penser l'esthétique littéraire, l’objet littéraire et son histoire. (2003: 11)

Tal horizonte tiene implicaciones profundas, incluso si, como expresa Nieves Baranda, el hecho de que "la historia literaria participe de los prejuicios de género no invalida ni mucho menos sus herramientas metodológicas" (2005: 134), que sí necesitan ser discutidas y reformuladas de tal forma que permitan incorporar aquella realidad hasta el momento excluida.

En lo que nos ocupa, esa realidad excluida es la obra de las escritoras. Con la finalidad de visibilizarlas e inscribirlas dentro de la historia literaria (por tanto, de crear y transmitir un capital simbólico ${ }^{12}$ ), la crítica feminista se ha preocupado especialmente de ellas, lo que no significa que no atienda igualmente a la producción de los escritores y que, como acabo de apuntar, en un movimiento de ma-

${ }^{12}$ Se trata de una necesidad vital. En un diálogo sobre poesía española contemporánea entre Concha García, Carlos Álvarez-Ude y Noni Benegas, esta última alude a esta necesidad: "Ellas [las poetas] sí que tienen conciencia de que han existido estas mujeres, pero a posteriori, no como formación [...]. Ahí está el problema [...] Muchas de ellas reciben el Adonais, por ejemplo, pero no se las toma en cuenta a la hora de elaborar la historia literaria [...]. Entonces las poetas no reciben ese capital simbólico de sus antecesoras" (García/ Benegas/ Álvarez-Ude, 1999).

UNED. REI, 4 (2016), pp. 9-41

ISSN 2340-9029 
yor alcance, lleve a cabo una revisión de toda esa serie de elementos y problemas que rodean el hecho literario y las instituciones que lo legitiman, aquellas que configuran y reproducen relatos maestros en los que las escritoras no han cabido. En última instancia, y al igual que otro tipo de lectura, la lectura feminista tiene como objetivo cualquier texto literario, lo que la singulariza es su posición crítica y sus categorías analíticas particulares.

Habría que recordar que en España le cabe a Emilia Pardo Bazán el privilegio de ser precursora en las dos líneas de producción crítica que determinarían los primeros pasos de la crítica literaria feminista, las que se llamarían, en el último tercio del siglo XX, “imágenes de la mujer" ${ }^{13}$ y "ginocrítica". Ambas son descritas por Elaine Showalter en su artículo de 1981 sobre escritoras inglesas del siglo XIX: "Feminist Criticism in the Wilderness". La primera concierne a las imágenes de los sujetos femeninos dentro de la obra de escritores (línea abierta por Kate Millett en su tesis doctoral Sexual Politics, de 1969) ${ }^{14}$, es decir, "se refiere a la feminista como lectora, y ofrece lecturas feministas de textos que examinan las imágenes y estereotipos de la mujer en la literatura"15, preocupándose por revelar la forma en que los varones escritores configuran sus personajes sometidos a los fun-

${ }^{13}$ En esta línea puede entenderse la interpretación hecha por Pardo Bazán de la Tristana de Galdós (Nuevo Teatro Crítico, 17 de mayo de 1892, pp. 77-90). La etiqueta ("imágenes de la mujer") corresponde a aquel momento: el uso de "mujer" en singular representando el signo (para una reflexión sobre este sentido, véase Celia Amorós, 1987). El título de Lola Luna "Leyendo como una mujer la imagen de la Mujer" (en mayúsculas) remite a esa idea. Más tarde el singular fue sustituido por e plural "mujeres", en tanto que más capaz de acoger todas las diversidades.

${ }^{14}$ La obra de Millett fue traducida al español en 1975, en México. Como señala Alicia Puleo (1994), se trata de una obra que aúna crítica literaria, antropología, economía, historia, psicología y sociología. Dividida en tres partes, es sobre todo en la tercera, "Consideraciones literarias", donde Millett analiza fragmentos de obras de D.H. Lawrence, Henry Miller, Norman Mailer y Jean Genet, contrastando las perspectivas entre los tres primeros y el último.

${ }^{15}$ Cito por la traducción española de Argentina Rodríguez: "La crítica feminista en el desierto", incluida en Fe (1999: 75-111), p. 78. Para otras denominaciones que emplea Showalter (literatura femenina, feminista, de mujer), véase Redondo Goicoechea (2001). damentos misóginos del imaginario patriarcal, binario, asimétrico y jerarquizado. La segunda vuelve su mirada hacia las obras de escritoras, recuperándolas del silencio, del abandono o del descrédito, y lo hace generalmente en estudios, historias y antologías independientes, segregadas de la historia literaria oficial que se ofrece como objetiva y neutral aunque en sus páginas solo se encuentren escritores.

Circulan, pues, en paralelo, algo que muchas veces, si nos referimos a las contemporáneas, disgusta a las propias escritoras. Pero, si es cierto que cabe una parte de razón en ese posicionamiento, también lo es la necesidad de emplear estrategias, que, cuestionables y mejorables, cumplan con el propósito que las mueve, el de contribuir a perfeccionar una historia que se ofrece sesgada e incompleta $y$, por lo tanto, falseada. Por otro lado, habría que preguntarse por los motivos que llevan a polemizar permanentemente sobre esta segregación, cuando nada se discute, en cambio, sobre tantas y tantas antologías e historias hechas sólo con nombres de escritores. Es ineludible, por todo ello, encarar el problema desde otros puntos de vista y dar la vuelta a los criterios y a las formas en que han sido abordados los hechos literarios y editoriales.

Faltarían por considerar algunos otros aspectos, entre ellos aquel que toca a la llamada "escritura femenina", hipótesis formulada y desarrollada en Francia por Hélène Cixous, y muy debatida ${ }^{16}$. Para Cixous (1995), que entiende la historia de la escritura como la historia de la razón — masculina-, la "écriture féminine" se opone a la lógica falocéntrica y parte del cuerpo y de la voz de la mujer, aspecto que se hará notar en las formas de los textos (en su disposición, en el lenguaje), lo que no deja de carecer de cierta peculiaridad si se tiene en cuenta que, en el planteamiento de Cixous, entre las características

${ }^{16}$ Otra francesa, Monique Wittig, se opuso tajantemente al concepto. Su argumentación se inscribe dentro de su disección radical del patriarcado y la heterosexualidad como régimen político: "es preciso decir que no existe la 'escritura femenina'. Utilizar y propagar esta expresión supone cometer un grave error [...] La 'escritura femenina' es la metáfora naturalista del hecho político brutal de la dominación de las mujeres" (2006: 85).

UNED. REI, 4 (2016), pp. 9-41

ISSN 2340-9029 
particulares del concepto estaba la de que el texto pudiera no haber sido escrito por una mujer.

Con el tiempo, y en bastantes ocasiones, este concepto, "escritura femenina", se ha desgajado de su origen y se ha generalizado haciéndose sinónimo de literatura (de autoría) femenina, por lo que no es nada extraño encontrar estudios donde se habla de escritura femenina, literatura femenina o escritura de mujeres. Es momento de repensar estas etiquetas y de abrir preguntas. Desde luego ¿por qué hablar de "mujeres escritoras" empleando una redundancia innecesaria? Pero también ¿hasta qué punto es ya productivo hablar de "escritura/literatura de mujeres" o de "literatura y mujeres" cuando, por el contrario, nunca se emplean las etiquetas simétricas "escritura/ literatura de hombres" o "literatura y hombres"? E incluso ¿qué significados puede movilizar hoy hablar de "literatura de mujeres" cuando las identidades de género están siendo reformuladas? Me parece muy pertinente, en este sentido, la siguiente reflexión de Ana Paula Ferreira:

Num momento em que uma das categorias fundamentales de identidade, ser mulher u homem, está sujetita a problematizaçoes teóricas que colocam sob suspeita o seu valor referencial, não é fácil reerguer o bastão realista de antigos projectos alarmados com a exclusão das mulheres de cánones literários estabelecidos. (2002: 13)

Aunque, tal como la propia Ferreira (2002: 14) argumenta: "não se pode contudo deixar de interrogar a ausência de mulheres da literatura" ${ }^{17}$ y ello porque la respuesta a ese interrogante, según la teoría feminista ha mostrado, nos coloca frente a todo un entramado de poder androcéntrico y misógino sobre el que se sustenta el sistema patriarcal, un sistema binario donde las categorías identitarias (la principal hombre/mujer) están sometidas a fuertes normas de producción y de actuación. Sigue siendo tiempo, por tanto, de cuestionar

${ }^{17}$ Reproduzco incompleta la frase de Ferreira, generalizando, al hacerlo, una observación que ella refiere concretamente a la literatura portuguesa de los años cuarenta. esa ausencia, pero, sin duda, es tiempo ya de superar viejos prejuicios y de dar entrada decidida a las escritoras en manuales, historias y reseñas críticas, poniendo el énfasis en su actividad y recorrido creativos. Se trata de encontrar nuevos enfoques desde los que categorizar y también etiquetar, pero nunca excluyendo o minusvalorando un texto en función de su autoría.

Me apropio de otras palabras de Iris M. Zavala (2002: 3) para cerrar este apartado: "El canon o lo canonizado no es un hecho ni biológico ni transhistórico sino una construcción discursiva contingente, y resultado de prácticas discursivas sobredeterminadas". No hay nada, pues, más que convenciones, intereses y valores detrás de su trazado, e interesa, y mucho, no ignorarlo.

\section{El valioso legado de la desobediencia}

Como se ha expuesto, y ateniéndonos a una perspectiva histórica, la crítica feminista puso el acento sobre las funciones e intencionalidad del canon, evidenciando sus presupuestos androcéntricos y su carácter interesado y removiendo sus postulados hasta el punto de provocar importantes transformaciones en algunas literaturas (caso de la inglesa, por ejemplo $)^{18}$. Eran las décadas finales del siglo veinte, pero el interés por el feminismo había comenzado mucho antes; $y$, aun mucho antes, se les llame feministas o no (ya que el uso de la palabra se difunde en el siglo diecinueve), habían comenzado las demandas de las mujeres y la defensa de sus iguales capacidades a las de los hombres, en un sentido político y en el que aquí interesa, el literario. Ningún obstáculo consiguió acallar las voces de aquellas mujeres que tenían como un objetivo absolutamente claro configurar una obra intelectual o artística acorde con sus planteamientos vitales e ideológicos, de manera que, frente a todos los inconvenientes, siguieron su camino, unas veces dentro de los moldes prefijados y otras cuestionándolos y transgrediéndolos, siempre reclamando su derecho

\footnotetext{
${ }^{18}$ Para una historia de las diferentes líneas y los diferentes momentos de la teoría literaria feminista, remito a Suárez Briones (2003).
}

UNED. REI, 4 (2016), pp. 9-41

ISSN 2340-9029 
a autorizarse y a ser autorizadas. Sus reivindicaciones y su resistencia constituyen un hilo no interrumpido que se consolida en el siglo $\mathrm{XX}^{19}$ al mismo tiempo que las teorías y la crítica feministas las canalizan y conceptualizan en un importantísimo corpus de pensamiento cada vez más complejo y con más ramificaciones, como lo exige la necesidad de atender a las múltiples facetas y variantes que se entrecruzan en la vida y la experiencia de los sujetos (sexo, cuerpo, sexualidad, raza, etnia, clase, edad) y que afectan a la/s identidad/es y a su control y regulación por parte de las instituciones de poder ${ }^{20}$.

Aunque se haya sostenido lo contrario, abundan las escritoras a lo largo de la historia. Es importante no olvidarlo. Los catálogos son elocuentes al respecto de su número. En el siglo XVII, Nicolás Antonio recoge algunas en su Bibliotheca Hispanae sive Hispanorum y da "noticia de 49 mujeres de letras" en un apéndice a la misma, el Gynaeceo Hispanae Minerva (Luna, 1996: 36). Avanzando los siglos, en los comienzos del veinte Manuel Serrano y Sanz publica sus Apuntes para una biblioteca de escritoras españolas desde el año 1401 a 1833 (1903) y, mucho más cercanamente, María del Carmen Simón Palmer Escritoras españolas del siglo XIX. Manual bio-bibliográfico (1991) y Escritoras españolas 1500-1900 (1992) ${ }^{21}$. Unos y otros textos nos recuerdan las cifras, al igual que para el siglo XVIII lo hacen los trabajos de Emilio Palacios (2002), García Garrosa (2007) o Mónica Bolufer (2009). Un hecho distinto es su presencia en las historias literarias. En un

19 Al historiar la creación literaria, tanto en sus períodos como en sus géneros, atendiendo a la obra de las escritoras es visible ese hilo sostenido y continuo de voces y de resistencias.

${ }^{20}$ Existen aportaciones interesantes sobre todas estas cuestiones en estudios tocantes a todas las épocas de la historia literaria, tanto la contemporánea como los siglos de Oro y la Edad Media (en cuanto a esta, mencionar las contribuciones de Eukene Lacarra sobre cuerpo y sexualidad; véase, por ejemplo, Lacarra 1999 y 2010). Hay que recordar que, sin formar parte del curriculum académico reglado, los estudios feministas y de género han entrado en las universidades de la mano de un importante número de grupos de investigación cuyos proyectos se incardinan a sus presupuestos teóricos y críticos.

${ }^{21}$ Simón Palmer introduce también los tres números de la revista Arbor dedicados a "Escritoras españolas del siglo XX" (719, 720 y 721, del año 2006). esclarecedor artículo sobre el trato recibido por las escritoras de la Edad Media y hasta el siglo XVIII en las historias literarias del siglo $\mathrm{XX}^{22}$, Nieves Baranda y $\mathrm{M}^{\mathrm{a}}$ del Carmen Marín concluyen:

Pese a que la crítica sobre las escritoras medievales y áureas se ha incrementado y se ha avanzado sustancialmente en el conocimiento de sus obras, las historias de la literatura, con muy pocas excepciones, siguen siendo muy conservadoras e inmovilistas e incorporan muy lentamente estos avances. (2005: 433)

Si esto es así actualmente, es fácil imaginar la situación en épocas precedentes. Por este motivo, entre otros, se hicieron necesarios trabajos específicos sobre las escritoras. En España, Pilar Oñate publica en 1938 El feminismo en la literatura española, que, por un lado, puede considerarse un estudio de "imágenes de la mujer", que abarca desde el ideal femenino transparentado en el Cantar de Mío Cid hasta algunas obras de autores del realismo decimonónico, contemplando, a lo largo de ese tiempo, las controversias entre posturas misóginas y posturas defensoras de las mujeres; y, por otro, se refiere a la obra de algunas autoras: santa Teresa, sor Juana, Margarita Hickey, Josefa Amar, Inés Joyes y Concepción Arenal ${ }^{23}$. En su conclusión, Oñate afirmaba:

Como restos fósiles de edades pasadas, todavía quedan antifeministas [...] Aún hay muchos hombres que solo ven en la mujer un objeto de placer [...] En todas partes y muy singularmente en nuestro país, todavía cuenta muchos adeptos la doctrina de que la mujer debe consagrase exclusivamente al hogar. Pero cada vez se impone más la realidad del feminismo. (Oñate, 1938: 237)

${ }^{22}$ Sobre repertorios e historias literarias véase además Baranda (2007).

${ }^{23}$ El libro de Pilar Oñate se encuentra accesible en la página de BIESES (Bibliografía de Escritoras Españolas): http://www.bieses.net/estudios-en-formato-digital/. Me parece interesante destacar que la autora emplee el término "feminista" en el título de la obra y que califique así a las escritoras estudiadas.

UNED. REI, 4 (2016), pp. 9-41

ISSN 2340-9029 
Y, en cuanto a la literatura:

la de la hora actual, lo mismo extranjera que española, trata a veces de temas feministas que considera, ya con seriedad, ya de un modo festivo, según el carácter del autor y la índole de la obra. El tema dominante suele ser la oposición entre el ejercicio de una profesión y la actividad peculiar de la mujer en el hogar. (238)

Precedieron a este texto de Pilar Oñate el de Thereza Leitão de Barros Escritoras de Portugal, publicado en Lisboa en 1924, y el de Margarita Nelken Las escritoras españolas (1930), trabajos pioneros en cuanto a la preocupación por hacer visibles a las escritoras dentro de la historia literaria y por explicar su ausencia en las mismas ${ }^{24}$. En cuanto al segundo, Nelken valora el prestigio de las escritoras en el seno de algunos movimientos, caso del Romanticismo ${ }^{25}$, aunque en ciertos momentos recurre a fórmulas similares a las empleadas por algunos varones canónicos para calificarlas ${ }^{26}$. Organizativamente, su trabajo posee dos aspectos destacables: por una parte, una voluntad explícita de no reducirse a un inventario de nombres, sino de presentar una selección de problemas y de autoras; y, por otra, el deseo de reunirlas no en agrupamientos de carácter cronológico, sino ideológico, algo que supone una variante significativa, incluso más allá de los resultados conseguidos. De hecho, cómo ordenar y agrupar a las escritoras o qué modelo de análisis utilizar para llevar a cabo esa tarea constituye todavía un problema al que dar respuesta y así lo

${ }^{24}$ Ambos libros pueden consultarse igualmente en la página de BIESES

25 "En Francia y en España diéronse los únicos movimientos románticos en que la colaboración femenina directa - es decir, no ya de inspiración, sino de participaciónalcanzó igual altura, gozó igual prestigio y ejerció igual influencia que la de los escritores varones $[\ldots]$ nombres sin los cuales la escuela romántica de estos países no podría escribirse" (1930: 188).

${ }^{26}$ Se refiere por ejemplo, a los "acentos varoniles" de Gertrudis Gómez de Avellaneda (como había hecho José Martí en una crónica de 1875 sobre Luisa Pérez de Zambrana: "No hay mujer en Gertrudis Gómez de Avellaneda: todo anunciaba en ella un ánimo potente y varonil") y a su apasionamiento: "Todas las mujeres apasionadas - ¿ Y cuál podría no serlo?_-" (189).

UNED. REI, 4 (2016), pp. 9-41 plantea Nieves Baranda. Con certeras reflexiones, y partiendo de la idea de que es preciso "respetar el principio de organización cronológica, pero no aplicado de un modo neutro [...], sino orgánico" (2005: 134), Baranda propone un método para las escritoras de la España Moderna ${ }^{27}$.

Ya hacia finales del siglo, la Breve historia feminista de la literatura española, coordinada por Iris M. Zavala, aúna estudios sobre obras de autoría femenina y masculina. En 1993 se publica su primer volumen ${ }^{28}$, donde, en tres ensayos teóricos (con firma de Rosa Rossi, Miriam Díaz Diocaretz y la propia Iris Zavala) se abordan cuestiones relativas al canon, la representación, los códigos literarios y la diferencia sexual. Le seguirán cinco volúmenes más hasta el año 2000. En su conjunto, la obra, que buscaba cubrir un espacio prácticamente inédito, se ofrece como una historia crítica cuyo objetivo es definido por Zavala del siguiente modo: "se trata de descolonizar el canon del patriarcado [sic], de re-apropiarlo y re-escribir las culturas restaurando sus silencios y las políticas y la lucha por el poder inscritos en los textos" (1993: 28) ${ }^{29}$. Con tal intención, se "afirmará no solo la producción cultural de las mujeres, sino la prioridad de la interpretación crítica de los textos literarios desde el margen y la diferencia, como actividad desmitificadora y descentralizadora" (1993: 35).

Como discursos culturales que son, los textos literarios llevan inscritos en su tejido, y los proyectan y revelan, los valores e intereses de la cultura en la que surgen. Entre ellos, obviamente, el complejo entramado de conductas y actitudes sobre la sexualidad que constituye la ideología sexual, en sus múltiples dimensiones, además de la compleja estructura de modelos y valores vinculados a las posiciones

27 "Historia de la escritoras españolas de la Edad Media al siglo XVIII (Una propuesta programática)” (Baranda, 2005: 123-174).

${ }^{28}$ Este primer volumen fue coordinado por Iris M. Zavala y Myriam Díaz Diocaretz. ${ }^{29}$ Dedicados a: "La mujer en la literatura española" "Modos de representación desde la Edad Media hasta el siglo XVII" y "Del siglo VIII a la actualidad) los volúmenes segundo y tercero; "La literatura escrita por mujer" ("De la Edad Media al siglo XVIII" y "Del siglo XIX a la actualidad") el cuarto y quinto, y a las literaturas peninsulares no castellanas (catalana, gallega y vasca) el sexto.

UNED. REI, 4 (2016), pp. 9-41

ISSN 2340-9029 
de poder, autoridad y norma. Como ya se ha dicho, desentrañar y revelar todas estas estructuras ha constituido uno de los mayores retos de la teoría y la crítica feministas, pero también lo ha constituido para quienes han configurado sus mundos de ficción desde posiciones atentas y disidentes con las normas de la cultura, una disidencia detectable a través de los modos de construcción de los personajes, de las relaciones entre ellos y de los valores que sustentan. En un sentido concerniente a estos aspectos, Zavala se refiere al problema de la representación:

El problema de la representación — tan importante para el otro, o para los Otros - es hoy por hoy uno de los conceptos centrales del feminismo y de las teorías culturales sobre la Otredad. No podemos desligar la representación [...] de las formas de hablar por el otro, de silenciar y de marginar. Y el otro al que me refiero de manera muy específica es la mujer.

(Zavala, 1993: 60)

Quién representa a quién, quién habla por quién, qué palabra ha legitimado la cultura, a quién le ha permitido hablar. Las voces de las escritoras y sus aportaciones fueron mayoritariamente sustraídas de la historia literaria, he insistido en ello, pero por circunstancias o intereses de diferente índole (políticos, religiosos, de clase) algunas se hicieron oír e incluso entraron en el canon. Ejemplo paradigmático sería el de Rosalía de Castro, referente de una literatura nacional excepcional en tanto que es ella, una escritora, su fundadora, si bien, expresivamente, su feminismo no fue contemplado por la crítica hasta hace bien pocos años ${ }^{30}$. Cuando Rosalía escribe su tan mencionado "Las literatas. Carta a Eduarda" (1865) está poniendo el dedo en una

${ }^{30}$ Al respecto, observa Helena González: "O sistema literario galego ofrece algunhas particularidades fronte a outros sistemas contiguos [...] ao ter unha muller, Rosalía como figura fundacional. Este feito condiciona poderosamente as relacións do discurso feminista co canon galego, porque [...] non se escribe desde a total negación, desde o non ser, nin desde a falta absoluta de modelos recoñecidos polo canon tradicional, senón desde a mitificación e manipulación dun modelo feminino inaugural, asimilado polo discurso patriarcal e desprovisto en parte do seu potencial subversivo como lexitimador da escrita das mulleres en galego" (2005: 44-45). herida supurante: la escasa valoración de la obra de las escritoras, cuando no el menosprecio, el rechazo y la anulación, pues se les niega la autoridad ${ }^{31}$. La ironía es palpable en el texto de la autora gallega a través del consejo que Eduarda da a su amiga Nicanora: escribe, si eso te hace feliz, pero olvídate de publicar. El problema radicaba ahí: en hacer pública una actividad que, para las mujeres, debía permanecer en el ámbito privado, confinada en el mismo espacio que ellas, el del hogar y las tareas domésticas ${ }^{32}$. Así lo exigía el imperativo social y cultural. Si acaso, como se anotó en páginas anteriores, podía darse algún portento, algún ejemplar femenino de "temperamento viril" cuya altura intelectual y creativa entraba en el ámbito público y no resultaba fácil de desdeñar; se trataba de excepciones, de singularidades $^{33}$, aunque ni siquiera ellas podrían alcanzar puestos reservados para quienes poseían la capacidad de detentarlos por el mero hecho "de tener barbas", en expresión sarcástica de Gertrudis Gómez de

${ }^{31}$ Una autoridad negada o discutida en muchos casos y durante mucho tiempo, o directamente robada (piénsese en las polémicas sobre Florencia Pinar y Oliva de Sabuco o, en el siglo XX, la cuestión de autoría y autoridad en relación con la obra de María de la O Lejárraga).

${ }^{32}$ Con ironía, Rosalía precisa que la actividad literaria no le hace abandonar sus obligaciones domésticas: "Sobre todo los que escriben y se tienen por graciosos, no dejan pasar nunca la ocasión de decirte que las mujeres deben dejar la pluma y repasar los calcetines de sus maridos, si lo tienen, y si no, aunque sean los del criado. Cosa fácil era para alguna abrir el armario y plantarle delante de las narices los zurcidos pacientemente trabajados, para probarle que el escribir algunas páginas no le hace a todas olvidarse de sus quehaceres domésticos, pudiendo añadir que los que tal murmuran saben olvidarse, en cambio, de que no han nacido más que para tragar el pan de cada día y vivir como los parásitos" (Castro, 1996: 494).

${ }^{33}$ En el siglo XVII para estas singularidades se empleaban epítetos diversos. Lo señala Margo Glantz (2009: 39): "Si la fama las aureola, su estatura se desmesura en tal grado que se transforman en mitos o en divinidades y en consecuencia se las designa como minervas, fénices, décimas musas, monstruos de la naturaleza", añadiendo: " $y$, aunque la hipérbole sea distintiva de la época barroca y el último epíteto le haya sido concedido también a otros poetas extraordinarios del Siglo de Oro, como Lope de Vega [...] cuando el superlativo se aplica a una mujer, se produce de inmediato un quiebre de sentido, se realza la anomalía y se insinúa la necesidad de enmendarla". En el siglo XIX se hablaba de temperamento viril, tal como evidencian los ejemplos. 
Avellaneda refiriéndose a los miembros de la Real Academia ${ }^{34}$, institución que, es sabido, cortó sus expectativas al negarle la entrada tanto a ella como, años más tarde, a Emilia Pardo Bazán ${ }^{35}$.

Hay que añadir, por otra parte, que los contenidos desarrollados por las escritoras han sido calificados de visiones particulares, carentes de la trascendencia y universalidad que se concede a los contenidos de los escritores ${ }^{36}$. Todo en contra. En ultima instancia, y como resume Cristina Peri Rossi: "Si el hecho de escribir confiere al escritor varón una aureola de sugestión personal adicional [...] el hecho de escribir cuestiona, en cambio, la identidad de la mujer que escribe" (1995: 4) ${ }^{37}$, de donde derivan las múltiples formas de sanción -descrédito, rechazo, ostracismo, inmasculación-y sus consecuencias - neurosis, locura, disfraz (caso de un seudónimo masculino), silencio-, de todas las cuales podrían ofrecerse múltiples ejemplos. La otra posibilidad, "asumir la ruptura, la transgresión con alegría y sin temor a los fantasmas del castigo" (Peri Rossi, 1995: 5), se consolidó a lo largo del siglo veinte, especialmente en su segunda mitad,

\footnotetext{
34 “esas ilustres corporaciones de gentes de letras, cuyo primero y más importante título es el de tener barbas" [Énfasis original] (Gómez de Avellaneda, 1871: 303).

35 Son hechos suficientemente conocidos. El 3 de febrero de 1853 Gómez de Avellaneda presenta ella misma su solicitud formal, que le es denegada (el día 10 del mismo mes los académicos, consultados, deciden no admitir a las mujeres en la Academia), y Pardo Bazán, aunque avalada por algunos miembros de la institución, obtuvo el mismo resultado negativo.

${ }^{36}$ Ya bien entrado el siglo veinte, la guatemalteca Ana María Rodas planteará as la cuestión en uno de los poemas de Poemas de la izquierda erótica: "Esto no sirve, dicen. / No es poesía porque hablo de máquinas. / De cocina [...] Dijeron que un poema / debería ser menos personal; / que eso de hablar de tú o yo / es cosa de mujeres. / Que no es serio" (Guatemala: Ediciones Testimonios del absurdo diario, 1973: 51-52)

${ }^{37}$ En la revista La Moda, número del 12 de noviembre de 1843, se decía: "El género neutro conocido vulgarmente bajo al dominación de literatas, que hablando con toda propiedad, y salvo algunas pocas excepciones, no son hombres ni mujeres" (apud Simón Palmer, 1990: 14). La consideración de "temperamento varonil", arriba indicada, o descripciones similares, a las que he aludido en otro momento de esta
} exposición, derivan de esta misma idea. aunque algunas figuras con personalidad extraordinaria ya lo habían hecho anteriormente, y algunas han sido nombradas.

En el punto de encuentro entre los siglos XIX y XX, época de reclamación de derechos (al voto, al divorcio, al aborto), y, por ello, época de manifiestos y de importante participación en prensa por parte de las escritoras, también en calidad de fundadoras y de directoras de revistas ${ }^{38}$, destaca la actividad de Carmen de Burgos como periodista de guerra, así como, en Portugal, la de Ana de Castro Osório (1872-1935), gran amiga de la anterior y que estuvo entre las fundadoras del Grupo Português de Estudos Feministas en $1907^{39}$. Dos años antes había publicado Ás Mulheres Portuguesas ${ }^{40}$, considerado el primer manifiesto feminista portugués (aunque su autora mantuvo posiciones de clase en relación con demandas de la clase proletaria y defendía un derecho al voto muy restrictivo para las mujeres).

Muchos otros nombres podrían señalarse en las primeras décadas del siglo, pero no pretendo realizar aquí ningún tipo de inventario, solamente dejar constancia de la participación de las escritoras en las reivindicaciones y debates de su época (debates sobre derechos pero también teóricos $)^{41}$, de modo semejante a lo que había sucedido

${ }^{38}$ Por poner dos ejemplos: en Portugal, Adelaida Cabete (1867-1935) funda y dirige Alma Feminina (1920-1929) y, en Cataluña, Carmen Karr Feminal (entre 1907 y 1917), suplemento del periódico La Ilustració Catalana (Muñoz, 2012). Por otro lado, como sabemos, la presencia de escritoras en la prensa fue muy significativa ya en la segunda mitad del siglo XIX, también en calidad de directoras, propietarias o fundadoras de revistas: Ángela Grassi y más tarde Joaquina García Balmaseda dirigen El Correo de la Moda (la primera entre 1867 y 1883, año de su muerte, y la segunda desde entonces); Concepción Jimeno de Flaquer El Álbum Ibero Americano (18911909); Pilar Sinués Flores y Perlas, y Faustina Sáez de Melgar La Violeta (18621866) (Palomo Vázquez, 2014). Casi todas estas revistas están accesibles a través de la Hemeroteca digital de la BNE.

${ }^{39}$ Una información detallada sobre el desarrollo del feminismo en Portugal puede verse en Ballesteros García (2002).

40 (Osório, 1905) Puede accederse a una versión digitalizada del texto en http:// purl.pt/13902/1/index.html\#/5/html. Sobre el papel de las escritoras portuguesas en relación con el feminismo véase Silva (1983).

${ }^{41}$ Piénsese en María Zambrano, en Rosa Chacel, en la catalana Victor Catalá 
a mediados del siglo XIX con el tema de la educación. Para todas ellas el espacio literario fue ese espacio de libertad que es, un territorio en el que es posible interrogarse, debatir y reflexionar a través de la configuración de modelos y universos alternativos y de desafío a todo tipo de convencionalismos; un territorio, en definitiva, donde alojar los cimientos de mundos más igualitarios.

Pero tanto en España como en Portugal (ambos países comparten este paralelo en su historia política) las dictaduras franquista y salazarista reprimirán e invalidarán los derechos conseguidos en esas primeras décadas. Será en los años setenta, expirando uno y otro régimen, cuando la palabra de las escritoras se expanda en la construcción de nuevas representaciones. De una forma decidida pasa a expresar todo aquello que, con todos los precedentes apuntados, ahora se transforma en clamor. Merece señalarse, en Portugal, la aparición de las Nuevas cartas portuguesas (1972), de María Isabel Barreno, María Teresa Horta y María Velho da Costa, que se convierte en estandarte de temas que ya no se quiere silenciar ni expresar con eufemismos, aunque tal osadía conllevó su castigo. La dictadura de Caetano retiró el libro del mercado y sus autoras fueron encarceladas por atentado a la moral pública, una moral a la que, en cambio, no le molestaba ni la misoginia ni la violencia y desigualdad derivadas de ella. La obra, sin embargo, fue traducida inmediatamente en Europa y en Estados Unidos ${ }^{42}$. En Francia lo fue en 1974 en las Éditions du Seuil, con prefacio de Evelyn Le Garrec y Monique Wittig, y en España en 1976 en la editorial Grijalbo ${ }^{43}$.

(seudónimo de Caterina Albert), en la canaria Mercedes Pinto, en todas las escritoras y artistas de la vanguardia y del 27.

${ }_{42}$ Para una información detallada sobre la historia del libro y su importancia dentro de las letras portuguesas e internacionales, remito a la página del proyecto que, coordinado por Ana Luísa Amaral, se constituyó a los cuarenta años de su publicación: http://www.novascartasnovas.com/. Véase también la introducción a la edición anotada y coordinada por Amaral (2010). Las tres autoras del libro ya habían publicado por separado obras donde los personajes femeninos desafiaban las normas y estereotipos fijados por la cultura patriarcal.

${ }^{43}$ En Portugal, el proceso a las autoras concluyó en 1974, con la caída de la dictadura de Caetano (Pereira, 2011).

UNED. REI, 4 (2016), pp. 9-41
También en España, a partir de los años setenta, se multiplica el número de escritoras, en todos los géneros literarios y en todas las lenguas del Estado. Sería imposible nombrarlas a todas, y, como escribí arriba, tal objetivo no se encuentra entre los de este artículo. Lo que sí me interesa señalar es cómo, aún hoy, algunas de estas descendientes de una genealogía que, en buena medida, cabría calificar de heroica, mantienen una relación bastante problemática con el feminismo. En su prefacio a The Feminist Encyclopedia of Spanish Literature, Janet Pérez y Maureen Ihrie, señalan:

feminist criticism as a discipline is in some respects still emerging from primeval chaos, divided into various national and ideological camps and not taken too seriously in Spain where a majority of women writers -including some of the most important exponents of feminist issues and writers on women's topics - reject the feminist label for varied and complex cultural and political reasons. (2002: viii)

Si décadas, incluso siglos, de reivindicaciones pudieran llevarnos a pensar lo contrario, la realidad es que escritoras de generaciones distintas siguen posicionándose actualmente en contra de una literatura feminista ${ }^{44}$, afirmando incluso, como hace Cristina Fernández Cubas, que "literatura y feminismo no tienen nada que ver" ${ }^{45}$. Y Soledad Puértolas añade (aunque sus palabras no tocan la cuestión feminista, sino la categoría "literatura de mujeres"):

O sea, que lo del sexo en la literatura me parece que no es lo adecuado. Me parece que lo de literatura de mujeres es un problema que estaría mejor planteado en un departamento de sociología, o de psicología; pero en un departamento de

${ }^{44}$ En la misma línea se había situado Carmen Martín Gaite, según menciona Jacqueline Cruz (2002: 252): "feminista, adjetivo que [...] resulta conveniente recordar, Martín Gaite siempre ha rehuido".

${ }^{45}$ Dicho por Fernández Cubas en un coloquio con Mercedes Abad, Soledad Puértolas y otras cuatro personas en la Universidad de California, Los Ángeles (Carmona et al, 1991). Son muy elocuentes los argumentos esgrimidos, sobre alguno de los cuales me detengo a continuación.

UNED. REI, 4 (2016), pp. 9-41

ISSN 2340-9029 
literatura no es un problema relevante, porque los problemas que tiene un escritor son iguales a los que tiene una escritora y el resultado de una obra se tendría que analizar de la misma manera. (Carmona et al., 1991: 159)

Incluso en el caso de que concordáramos con lo dicho por estas autoras, no puede negarse que hombres y mujeres no son sino el efecto de la distribución binaria de los roles sociales del patriarcado, lo que supone que la intrahistoria del ejercicio literario se mantiene, para muchas escritoras, en términos similares a los de sus predecesoras, desmintiendo algunas de las aseveraciones de Puértolas. María del Mar López Cabrales recoge de la siguiente forma el sentir de Juana Salabert (desde el que no resulta difícil evocar el pensamiento de Rosalía de Castro, Pardo Bazán o Alfonsina Storni, un siglo y siglo y medio antes):

Juana Salabert dijo que es más difícil ser escritora que escritor, porque los hijos y la sociedad reconocen esta profesión en el hombre, pero no en la mujer. Salabert explicaba que, en familias de conocidos/as, cuando el padre está escribiendo, está 'trabajando' y se le respeta. Su experiencia como madre y escritora es muy diferente. (López Cabrales, 2014: 442)

Al mismo tiempo, la propia López Cabrales expresa su sorpresa ante los resultados de unas entrevistas en las que se pone de relieve el rechazo, por una parte significativa de las escritoras entrevistadas, a que sus obras sean calificadas como feministas o simplemente "de mujeres":

Los resultados [...] fueron sorprendentes, y hasta cierto punto contradictorios. En primer lugar, fue unánime la aversión que estas escritoras sienten hacia la posibilidad de que sus obras sean catalogadas bajo epígrafes como 'literatura feminista' o 'literatura de mujeres'. El primero porque 'feminista' se asocia popularmente a una postura política radical, o incluso a lesbianismo, y el segundo porque la literatura 'de mujeres' es percibida como un subgénero plagado de estereotipos de menor calidad que la literatura con mayúsculas, asociada en general a la producción de autores de género masculino. Ellas desean ser conocidas como escritoras simplemente, sin ningún tipo de connotación o concepto. (López Cabrales, 2014: 440)

Reveladoras palabras, tanto como expresión de un ideal cuanto al respecto de varias de las cuestiones que he ido planteando a lo largo de esta exposición. Por un lado, no puede obviarse que el hecho de que las mujeres escriban y publiquen hoy con naturalidad es el resultado del coraje y la energía desplegada por sus antepasadas; por otro, tampoco, el de que son herederas de un pasado de exclusiones $y$ de falta de autoridad que esas etiquetas recuerdan ${ }^{46}$, etiquetas que, por factores de otra índole, y como se ha visto, también resulta imprescindible interrogar. Si ser catalogada bajo la marca "literatura de mujeres" significa ser colocada al margen de la tradición ${ }^{47}$ y de la literatura con mayúsculas, representada por la obra de los escritores, el mejor argumento es considerar que la literatura no tiene sexo, que solo existe la buena o la mala literatura, olvidando o eludiendo y, por tanto, ocultando que el hecho literario y todo lo que lo rodea forma parte de las mismas estructuras de poder que los demás hechos de la vida y de la cultura: que "aquella terrible permanente presencia del sexo en toda cosa que la mujer hace para el público, todo contribuye a aplastarnos" 48 , mientras que, para los hombres, como si tratara de

46 "El mero concepto de literatura femenina, efectivamente, es un concepto discriminatorio que, por sí mismo, consiste en reconocer el carácter marginal de lo femenino o el carácter desvalorizado o inferior de lo femenino, no inferior por sí mismo sino inferior dentro de nuestra cultura. Por lo cual yo entiendo muy bien que muchas escritoras lo rechacen" (Palabras de Laura Freixas; en Santamaría, 2002). ${ }^{47}$ De la tradición patriarcal, obviamente. Así lo recuerda Juana Castro (2003: 57): "Cuando llegamos a la escritura nos encontramos con toda una tradición patriarcal. Pero también hay otra tradición, la de las mujeres escritoras que nos precedieron, y que tantas veces nos ha sido escamoteada".

${ }_{48}$ Palabras de Alfonsina Storni en una carta a su amigo Julio Cejador, en la que añadía: "Si logramos sostenernos en pie es gracias a una serie de razonamientos con que cortamos las malas redes que buscan envolvernos; así pues, a tajo limpio nos mantenemos en lucha. 'Es una cínica' dice uno. 'Es una histérica' dice otro. Alguna voz aislada dice quedamente 'es una heroína”' (Pérez Blanco, 1975: 41).

UNED. REI, 4 (2016), pp. 9-41

ISSN 2340-9029 
ángeles asexuados, nada de esto tiene relevancia: su particularidad se extiende hasta la universalidad, identificándose con ella y representando la centralidad y la medida de una supuesta neutralidad.

Muy diferente es el caso de "literatura feminista", pues literatura feminista no es, y no puede ser entendido de ese modo, sinónimo de literatura sobre mujeres o para mujeres o de un tipo de literatura panfletaria: la literatura feminista implica un planteamiento, una perspectiva, una conciencia y una posición crítica sobre las cuestiones de género. Y con esos elementos como marco se fabrican las actuaciones y relaciones de los personajes, el mundo visibilizado, las coordenadas y parámetros de ese mundo y la mirada reflexiva o crítica sobre el mismo, el rechazo a los estereotipos y la consignación de modelos que les hagan frente. Está claro para otras muchas escritoras. La literatura (y de igual forma podría decirse la crítica) no tiene sexo, pero quien la escribe $\operatorname{si}^{49}$, y sexo y género se han constituido en experiencia social y de vida, construidos y afianzados a través de los férreos mandatos de la cultura. En tanto que construcciones, sin embargo, tal y como teoría y filosofía se han encargado de argumentar, pueden ser desmontadas, y los textos literarios, y reitero lo expresado en otro momento de estas páginas, como discursos culturales pueden aportar modelos, estrategias $\mathrm{y}$, sobre todo, razonamientos y análisis conducentes a la erradicación de esos mandatos. Literatura y femismo, por consiguiente, y por encima de cuestionamientos y disensiones, ha resultado ser una conjunción muy fructífera.

Recibido: $26 / 10 / 2016$

Aceptado: 28/11/2016

${ }^{49}$ Evoco palabras de la escritora uruguaya Sylvia Lago: "En mi opinión, la literatura no tiene sexo, pero quienes la escriben sí lo tienen" (Flori, 2002: n.p.).

UNED. REI, 4 (2016), pp. 9-41

\section{Referencias bibliográficas}

Amaral, Ana Luísa (2010), "Breve introdução” a Novas cartas portuguesas, Alfragide/Portugal: Publicações Dom Qixote, pp. XV-XXVIII.

Amorós, Celia (1987), "Espacio de los iguales, espacio de las idénticas: notas sobre poder y principio de individuación", Arbor, 503-504, pp. 113-128.

Bahar, Saba; y Cossy, Valerie (2003), "Le canon en question: l'objet littéraire dans le sillage des mouvements féministes", Nouvelles Questions Féministes, 22/2, pp. 4-12.

Ballesteros García, Rosa Ma (2002), "El despertar de un movimiento social: el feminismo en Portugal", en $\mathrm{M}^{\mathrm{a}}$ Dolores Ramos y $\mathrm{M}^{\mathrm{a}}$ Teresa Vera coords., Discursos, realidades, utopías. La construcción del sujeto femenino en los siglos XIX y XX, Barcelona: Anthropos, pp. 165-212.

Baranda, Nieves (2005), Cortejo a lo prohibido. Lectoras y escritoras en la España moderna, Madrid: Arco/Libros.

- (2007), "Desterradas del parnaso", Bulletin Hispanique, 109-2, pp. 421-447. Accesible en http://bulletinhispanique.revues.org/236 [consulta 20/06/2016].

- y Ma Carmen Marín (2006), "Bibliografía de escritoras españolas (Edad Media-Siglo XVIII). Una base de datos", en Anthony Close ed., Edad de oro Cantabrigense: Actas del VII Congreso de la Asociación Internacional Siglo de Oro (AISO). Robinson College, Cambridge, 18-22 julio, 2005, Cambridge: Asociación Internacional del Siglo de Oro, pp. 425-435. Accesible en http://cvc.cervantes.es/literatura/aiso/ pdf/07/aiso_7_061.pdf [consulta 20/ 05/ 2016].

Barreno, Maria Isabel; Horta, Maria Teresa; Costa, Maria Velho da (1972), Novas cartas portuguesas, Alfragide/Portugal: Publicações Dom Qixote, 2010

Barros, Thereza Leitão de (1924) Escritoras de Portugal: génio feminino revelado na literatura portuguesa, Lisboa: Tipografia de A.O. Artur. Accesible en http://www2.uned.es/bieses/Leitao/Leitao-1.pdf 
Bolufer, Mónica (2009), "Mujeres de letras. Escritoras y lectoras en el siglo XVIII", en Rosa $\mathrm{M}^{\mathrm{a}}$ Ballesteros y Carlota Escudero (eds.), Feminismos en las dos orillas, Málaga: Universidad de Málaga, pp. 113-141. Accesible en <http://www.cervantesvirtual.com/obra/mujeres-de-letras-escritoras-y-lectoras-del-siglo-xviiiAc--0/ [consulta $15 / 06 / 2016]$.

Carmona, Vicente et al. (1991), "Conversando con Mercedes Abad, Cristina Fernández Cubas y Soledad Puértolas: 'Feminismo y literatura no tienen nada que ver"', Mester, 20/2, pp. 157-165.

Castro, Rosalía de (1996), Obra completa, Padrón/A Coruña: Fundación Rosalía de Castro.

Castro, Juana (2003), "Escritura de mujeres y tradición. Tres lecturas", Duoda. Revista d'Estudis Feministes, 24, pp. 57-72.

Cixous, Hélène (1995), La risa de la Medusa: ensayos sobre la escritura, Barcelona: Anthropos [1 $1^{\text {a }}$ ed. francés 1975].

Cruz, Jacqueline (2002), "Replegando la voz: Carmen Martín Gaite y la cocina de la escritura", en Barbara Zecchi y Raquel Medina eds., Sexualidad y escritura (1850-2000), Barcelona: Anthropos, pp. 249269.

Cuevas, Cristóbal (2000), "Palabras liminares", Actas del XIII Congreso de Literatura Española Contemporánea, Málaga: Publicaciones del Congreso de Literatura Española Contemporánea, pp. 7-11.

Darío, Rubén (1901), "La mujer española”, en España contemporánea, París: Garnier Hermanos, pp. 376-384. Accesible en https://archive. org/details/espaacontempor00dar [consulta 20/07/2016].

- (1912), “¡Estas mujeres!”, en Todo al vuelo, Madrid: Renacimiento, pp. 34-36. Accesible en https://archive.org/details/todoalvuelo00dar [consulta 20/07/ 2016].

Fe, Marina (1999), Otramente: lectura y escritura feministas, México: FCE.

Ferrerira, Ana Paula (2002), "A 'literatura feminina' dos anos cuarenta: uma história de exclusão", introduccion a A urgência de contar: contos de mulheres dos anos 40, Lisboa: Editorial Caminho.

Flori Mónica (2002); "Sylvia Lago: la literatura no tiene sexo pero quienes la escriben sí" [entrevista], Espéculo. Revista de Estudios Literarios, 21, n.p., en línea: https://pendientedemigracion.ucm.es/info/ especulo/numero21/s_lago.html

Freixas, Laura (2005), "Mujeres y cultura: una breve arqueología de la misoginia reinante", Letras libres, 49, pp. 36-39.

- (2007) "Los libros, ¿cosa de mujeres?", El País (3 abril). Accesible en http://elpais.com/diario/2007/04/23/cultura/1177279202_850215. html [consulta 10/09/2016].

- (2008), "La marginación femenina en la cultura", El País (3 mayo) . Accesible en http://elpais.com/diario/2008/05/03/opinion/1209765613_850215.html [consulta 10/09/2016]

- (2009), La novela femenil y sus lectrices, Córdoba: Universidad de Córdoba.

- (2013), "Qué fue de las escritoras", El País (6 julio). Accesible en http://elpais.com/elpais/2013/06/25/opinion/1372182616_612684. html [consulta 10/09/2016].

García, Concha; Benegas, Noni; y Álvarez-Ude, Carlos (1999), "El estado de la cuestión. Poetas españolas en el fin de siglo", Insula, 630, pp. 7-14. . Accesible en http://insula.es/sites/default/files/articulos_ muestra/INSULA\%20630.htm [consulta 15/ 09/ 2016].

García Garrosa, María Jesús (2007), "La creación literaria femenina en España en el siglo XVIII: un estado de la cuestión", Cuadernos de Historia Moderna, Anejo VI, pp. 203-219. Accesible en: http://revistas.ucm.es/index.php/CHMO/article/view/CHMO0707220203A [consulta 10/09/2016].

Glantz, Margo (2009), "Androginia y travestismo en la obra de María de Zayas", en Irene Albers y Uta Fenten eds., Escenas de transgresión: 
María de Zayas en su contexto literario-cultural, Madrid/ Frankfurt: Iberoamericana/Vervuert, pp. 35-63.

Gómez de Avellaneda, Gertrudis (1871), "La Mujer. Artículos publicados en un periódico el año de 1860 , y dedicados por la autora al bello sexo", en Obras literarias. Tomo 5, Novelas y leyendas, Madrid: [s.n.] Imprenta y Estereotipia de M. Rivadeneyra, pp. 283-306. Accesible en http://www.cervantesvirtual.com/servlet/SirveObras/ p248/12368307710169384987213/index.htm [consulta 15/08/2016].

González, Helena (2005), Elas e o paraugas totalizador. Escritoras, xéreno, nación, Vigo: Xerais.

González de Amezúa, Agustín (1950), "Prólogo" a María de Zayas, Desengaños amorosos, Madrid: RAE, pp. vii-xxiv.

Joaquim, Teresa (2004), "Ex Aequo: contributo decisivo para um campo de estudos em Portugal", Revista de Estudos Feministas, 12, PP. 88-93. Accesible en http://www.scielo.br/scielo.php?pid=S0104026X2004000300009\&script=sci_arttext [consulta 15/06/2016].

Lacarra, Eukene (1999), "Sobre la evolución del discurso del género y del cuerpo en los Estudios medievales (1985-1997)", en Santiago Fortuño Llorens y Tomás Martínez Romero eds., Actes del VII Congrés de L'Associacio Hispànica de Literatura Medieval, Castelló de la Plana: Publicaciones de la de la Universitat Jaume I, vol I, pp. 61-100.

- (2010), "Representaciones de homoerotismo femenino en algunos textos literarios medievales", Estudios humanísticos. Filología, 32, pp. 81-103.

López Cabrales, María del Mar (2014), "Nuevas cuentistas españolas frente al feminismo: Teoría y producción”, Bulletin Hispanique, 116-1, pp. 438-449.

Luna, Lola (1996), Leyendo como una mujer la imagen de la Mujer, Barcelona: Anthropos.

Méndez, Lourdes, (2005), "Una connivencia implícita; 'perspectiva de género', 'empoderamiento' y feminismo institucional”, en Rosa An- drieu Sanz y Cermen Mozo González eds., Antropología feminista y/o de género. Legitimidad, poder y usos políticos, Sevilla: El Monte / Asociación Andaluza de Antropología, pp. 203-226. Accesible en http:// www.pensamientocritico.org/loumen0306.html [consulta 20/06/ 2016].

Muñoz, Ana (2012), "La revista Feminal: paradigma de las publicaciones feministas españolas de principios del siglo XX", El Futuro del Pasado, 3, pp. 91-105. Accesible en http://www.elfuturodelpasado.com/ ojs/index.php/FdP/article/view/102 [consulta 5/08/2016].

Nelken, Margarita (1930), Las escritoras españolas, Barcelona et al: Labor. Accesible en http://www.bieses.net/estudios-en-formato-dgital/ [consulta 20/05/2016].

Oñate, $M^{a}$ del Pilar (1938), El feminismo en la literatura española, Madrid: Espasa-Calpe. Accesible en http://www.bieses.net/estudiosen-formato-digital/ [consulta 20/05/2016].

Osório, Anna de Castro (1905), Ás mulheres portuguesas, Lisboa: Editora Viúva Tavares Cardoso.

Palacios Fernández, Emilio (2002), La mujer y las letras en la España del siglo XVIII, Madrid: Laberinto. Accesible en http://www.cervantesvirtual.com/obra-visor/la-mujer-y-las-letras-en-la-espana-delsiglo-xviii--0/html/01 ee5680-82b2-11df-acc7-002185ce6064.html [consulta 15/09/ 2016].

Palomo Vázquez, Ma Pilar (2014), "Las revistas femeninas españolas del siglo XIX. Reivindicación, literatura y moda", Arbor, vol. 190, no 767. Accesible en: http://arbor.revistas.csic.es/index.php/arbor/article/viewArticle/1932/2213 [consulta 20/09/2016].

Pardo Bazán, Emilia (1999), La mujer española y otros escritos, Madrid: Cátedra.

Pereira, María de Lourdes (2011), "De Mariana Alcoforado a las Tres Marías, un camino de coraje y resistencia a partir de la palabra”, $R e$ vista Internacional de culturas y literaturas, 2: http://www.escritorasyescrituras.com/revista-detalle.php/11/99/de-mariana-alcoforado-

UNED. REI, 4 (2016), pp. 9-41

ISSN 2340-9029 
a-las-tres-maras-un-camino-de-coraje-y-resistencia-a-partir-de-lapalabra [consulta 20/07/2016].

Pérez, Janet y Maureen Ihrie, eds. (2002), The Feminist Encyclopedia of Spanish Literature, Westport, Connecticut/London: Greenword Press.

Pérez Blanco, Lucrecio (1975), La poesía de Alfonsina Storni, Madrid: edición del autor.

Peri Rossi, Cristina (1995), “Escribir como transgresión”, Lectora, 1, pp. 3-5.

Puleo, Alicia (1994), "El feminismo radical de los setenta: Kate Millett”, en Celia Amorós coord., Historia de la teoría feminista, Madrid: Universidad Complutense / Dirección General de la Mujer, pp. 139. 149.

Redondo Goicoechea, Alicia (2001),"Introducción literaria. Teoría y crítica feministas", en Cristina Segura Graíño coord., Feminismo y misoginia en la literatura española. Fuentes literarias para la Historia de las Mujeres, Madrid: Narcea, pp. 19-46.

Santamaría, Isabel (2002), "Las mujeres y la literatura para Laura Freixas", Página abierta, 126. Accesible en http://www.pensamientocritico.org/isasan0502.html [consulta 20/09/2016].

Serrano y Sanz, Manuel (1903-05), Apuntes para una biblioteca de escritoras españolas desde el año 1401 a 1833, Madrid: Rivadeneyra, 2 ts.

Showalter, Elaine (1981), "Feminist criticism in the wilderness", Critical Inquiry, 8, 1, pp. 179-205.

Simón Palmer, María del Carmen (1990), "Panorama general de las escritoras románticas españolas”, en Marina Mayoral coord., Las escritoras románticas españolas, Madrid: Fundación Banco Exterior, pp. 9-16.

- (1991), Escritoras españolas del siglo XIX. Manual bio-bibliográfico, Madrid: Castalia.
- (1992), Escritoras españolas 1500-1900, Madrid/Londres: Biblioteca Nacional/Chadwyck-Healey.

Silva, Maria Regina Tavares da (1983), "Feminismo em Portugal na voz de mulheres esritoras do início do século XX”, Análise Social, 7778-79, pp. 875-907. Accesible en http://analisesocial.ics.ul.pt/docum entos/1223465449P2eYY6he7Ah47BN7.pdf [consulta 20/07/2016].

Suárez Briones, Beatriz (2003), Sextualidades: Teoría literarias feministas, Alcalá de Henares: Ayuntamiento Alcalá de Henares/Centro Asesor de la Mujer.

Wittig, Monique (2006), El pensamiento heterosexual y otros ensayos, Madrid/Barcelona: Egales.

Zavala, Iris M. (1993), "Las formas y funciones de una teoría crítica feminista. Feminismo dialógico", en Myriam Díaz Diocaretz e Iris M. Zavala coords., Breve historia feminista de la literatura española (en lengua castellana). I. Teorías feministas: discursos y diferencias, Madrid: Anthropos /Comunidad de Madrid, pp. 13-76.

- (2002), "De la pluralidad de los cánones y la imposibilidad de lo Uno”, La Página, 48, pp. 3-14. 